\title{
Behavioral Pattern during Dental Pain in Intellectually Disabled Children: A Comparative Study
}

\author{
Muthukali Shanmugam, Vetrivel Shivakumar, Vijayarangan Anitha, \\ Bagavathi Perumal Meenapriya, Srinivasan Aishwarya, and Ramakrishnan Anitha
}

\author{
Department of Periodontics, Chettinad Dental College \& Research Institute, IT Highway, Rajiv Gandhi Salai, \\ Kelambakkam, Chennai, Tamil Nadu 603112, India \\ Correspondence should be addressed to Muthukali Shanmugam; drshanmds@yahoo.co.in
}

Received 29 April 2014; Accepted 3 November 2014; Published 18 November 2014

Academic Editor: Qi Zhang

Copyright (C) 2014 Muthukali Shanmugam et al. This is an open access article distributed under the Creative Commons Attribution License, which permits unrestricted use, distribution, and reproduction in any medium, provided the original work is properly cited.

\begin{abstract}
Aim. Children with developmental disabilities generally experience more pain than the normal children. Description of pain is generally difficult in children and more so in children with intellectual disabilities. The study aimed at evaluating dental pain in children with intellectual disabilities. Methods. The survey was carried out in an institution caring for intellectually disabled children to determine the oral health status and the treatment needs of the special kids. 236 children were surveyed out of which the test group is comprised of 111 intellectually disabled children and the control group had 125 normal children with age ranging between five to eighteen years. A questionnaire was presented to the caregivers to elaborate about dental pain in their wards using the dental discomfort questionnaire (DDQ+). The children were examined for dental caries and periodontal status based on the WHO indices for oral hygiene status. Result. Results revealed a statistically significant difference between intellectual disability and brushing, chewing, and earache. The frequency of reporting dental pain was lesser in the intellectually disabled group. Conclusion. Children with intellectual disability tended to report dental pain of any nature with lesser frequency than typically developing peers. They also faced greater difficulty in brushing and chewing.
\end{abstract}

\section{Introduction}

Pain is a highly complex, dynamic, subjective experience that is useful in growing children, serving to warn them of danger and limiting exposure to additional injury. Children learn to prevent and cope with pain [1]. However, untreated, acute, or recurrent or chronic pain may have significant and lifelong consequences (both physiologically and psychologically). The first step in treatment process is accurate diagnosis of the problem. Since pain is an inherently subjective phenomenon, it is often said that the gold standard for pain assessment in both children and adults is verbal reporting [1-3]. It is the only way to determine the intensity and quality of the pain present. However, reliable description in children especially in intellectually disabled (ID) children is very difficult.

Children often confuse pain with fear and anxiety due to their cognitive impairment. Children with intellectual disability have an added challenge of not being able to express the pain or verbalize it [3].

Cognitively impaired children usually rely on their caregivers to interpret their distress. Hence, to gather pain relevant information, caregivers were interviewed regarding their children for expression of pain, experience, treatment, and coping behavior. Research shows that children with developmental disabilities generally experience more pain than the normal children due to chronic systemic conditions associated with their disability [4-6]. Their pain is never properly expressed because of their lack of verbal communication. Many children have idiosyncratic behaviors such as moaning/grunting which may lead to over/underestimation of pain [6].

The aim of the study was to evaluate the dental pain in children with intellectual disabilities from a caregiver's perspective. 


\section{Materials and Methods}

The study was initiated after obtaining clearance from the Institutional Ethics Committee, Chettinad Health City. Informed consent was obtained from the subjects prior to start of the study.

The study was carried out on a total of 236 children. Study group is comprised of 111 intellectually disabled children. They were residing at Vasantham institution for intellectually disabled children, Mogappair, Chennai, Tamil Nadu, India. The children had intellectual disability in the mild, moderate range [7]. The control group included 125 typically developing peers from Mambakkam, Chennai, India. All the children in the control group were of normal intellectual growth as determined by their academic evaluations.

\subsection{Selection Criteria}

(1) Age group ranged from 5 to 18 years.

(2) The study group has a history of intellectual disability as verified by the child's medical file or caregivers reporting.

(3) Caregivers were able to understand spoken English/ Tamil.

(4) The control group included children who had normal intellectual development.

Four investigators were assigned to do intra- and extraoral examination on the children. The nature of the study was explained and the investigators assisted them in filling the questionnaire.

2.2. Questionnaire. To assess the change in behavior in intellectually disabled children during tooth ache, a Dental Discomfort Questionnaire (DDQ+) was developed. The questionnaire was drafted after extensive interviews with parents or caregivers of children with pain by Versloot et al. The DDQ+ has a good predictive value for the incidence of toothache [8]. The questionnaire was distributed to all the subjects participating in the study.

A lot of questions relating to the behavior of intellectually disabled children were added to the DDQ+. The questionnaire was filled during the interviews by the caregivers with the help of the investigators. The language used was Tamil/English. The questions were tabulated and the caregivers had to select the most appropriate option that explained the occurrence of pain/discomfort in children. The options were "never" (scored as zero), "occasionally" (scored as one), and "always" (scored as two). A total numeric mean for each child and a mean of the DDQ+ for the group were calculated.

Caregivers and investigators were also asked to rate the child's dental pain on a ten point scale where "zero" represented the absence of pain and "ten" the maximum pain imaginable [9]. The scale was converted to an ordinal scale with never, mild, moderate, and severe categories. Never represented the absence of pain (score 0). Mild pain was when the rating was between 1 and 3 , moderate was between
TABLE 1: DMFT and dft scores in children with ID and normal children.

\begin{tabular}{lccccc}
\hline $\begin{array}{l}\text { DMFT } \\
\text { component }\end{array}$ & $\begin{array}{c}\text { Disabled } \\
\text { mean } \pm \text { SD }\end{array}$ & $\begin{array}{c}\text { Normal } \\
\text { mean } \pm \text { SD }\end{array}$ & $t$-value & df & $P$ value \\
\hline Decayed (D) & $0.64 \pm 1.32$ & $1.06 \pm 1.40$ & 2.33 & 234 & 0.02 \\
Missing (M) & $0.68 \pm 2.23$ & $0.03 \pm 0.21$ & 3.2 & 234 & 0.002 \\
Filled (F) & $0.14 \pm 0.72$ & 0 & 2.1 & 234 & 0.037 \\
Decayed (d) & $0.08 \pm 0.38$ & 0 & 2.35 & 234 & 0.019 \\
Filled (f) & 0 & 0 & 0 & 0 & - \\
\hline
\end{tabular}

4 and 7 , and severe pain was between 8 and 10. The dental examinations were conducted using a dental explorer to detect dental caries. The caries examination was based on the "WHO" criteria according to which the DMFT/dft (decayed, missing, and filled teeth) indices were scored. A frank cavitation which is a break of $0.5 \mathrm{~mm}$ or more into enamel was considered as caries. Any incipient or questionable caries were not included. Any teeth filled with any restoration except sealants were considered as "filled" teeth. The "m" was not included in $\mathrm{dft}$ because children have mixed dentition.

2.3. Statistical Analysis. The statistical analysis was done using Windows SPSS software version 16. All the data was reported as mean \pm standard deviation (SD). Student's $t$-test, degree of freedom, mean and standard deviation, and chisquare test were analyzed. The level of significance $(P)$ was set at 0.05 .

\section{Results}

3.1. Demographic Data. The sample investigated in this study was a total of 236 children, out of which 111 were intellectually disabled children and 125 were healthy children. The study involved 151 males and 85 females. The age group of the sample ranged from 6 to 15 years.

3.2. Dental Findings and Pain Data. The DMFT and $\mathrm{dft}$ scores of the sample investigated were tabulated (Table 1). The DMFT score was higher in intellectually disabled (ID) children. The difference in the number of filled teeth between the study and control group was negligible. The dft score was increased in normal healthy children as opposed to disabled children.

The investigators put forward questions describing the specific behavioral pattern of the children experiencing dental pain. These questions were presented to the caregivers in order to find out the perception of dental pain between the control and study group and whether it was comparable. The behavioral pattern which was specifically exhibited by the children during dental pain was documented as per the caregiver's perception. Outcome of the tabulation in this study showed that ID children had problems in brushing teeth especially the upper teeth and it was statistically significant $(P=0.00)$. The other significant change during pain included biting with the molar instead of the other teeth $(P=0.001)$. Most of the ID children reached for the cheek 
TABLE 2: Comparison of DDQ between children with intellectual disability and normal children.

\begin{tabular}{|c|c|c|c|c|c|c|c|}
\hline \multirow{2}{*}{ Question } & \multirow{2}{*}{ Frequency } & \multicolumn{2}{|c|}{ Disabled children } & \multicolumn{2}{|c|}{ Normal children } & \multirow{2}{*}{ Chi-square } & \multirow{2}{*}{$P$ value } \\
\hline & & $n$ & $\%$ & $n$ & $\%$ & & \\
\hline \multirow{3}{*}{ Problems with brushing upper teeth } & Never & 29 & 26.1 & 110 & 88 & \multirow{3}{*}{94.25} & \multirow{3}{*}{$0.000^{*}$} \\
\hline & Occasionally & 79 & 71.2 & 13 & 10.4 & & \\
\hline & Always & 3 & 2.7 & 2 & 1.6 & & \\
\hline \multirow{3}{*}{ Problems with brushing lower teeth } & Never & 39 & 35.1 & 115 & 92 & \multirow{3}{*}{84.4} & \multirow{3}{*}{$0.000^{*}$} \\
\hline & Occasionally & 70 & 63.1 & 9 & 7.2 & & \\
\hline & Always & 2 & 1.8 & 1 & 0.8 & & \\
\hline \multirow{3}{*}{ Puts away something nice to eat } & Never & 106 & 95.5 & 109 & 87.2 & \multirow{3}{*}{5.49} & \multirow{3}{*}{$0.06^{\dagger}$} \\
\hline & Occasionally & 5 & 4.5 & 14 & 11.2 & & \\
\hline & Always & 0 & 0 & 2 & 1.6 & & \\
\hline \multirow{3}{*}{ Bites with molar instead of front teeth } & Never & 100 & 90.1 & 95 & 76 & \multirow{3}{*}{9.27} & \multirow{3}{*}{$0.010^{*}$} \\
\hline & Occasionally & 10 & 9 & 22 & 17.6 & & \\
\hline & Always & 1 & 0.9 & 8 & 6.4 & & \\
\hline \multirow{3}{*}{ Chewing at one side } & Never & 96 & 86.5 & 105 & 84 & \multirow{3}{*}{1.511} & \multirow{3}{*}{$0.47^{\dagger}$} \\
\hline & Occasionally & 14 & 12.6 & 16 & 12.8 & & \\
\hline & Always & 1 & 0.9 & 4 & 3.2 & & \\
\hline \multirow{3}{*}{ Problems in chewing } & Never & 95 & 85.6 & 115 & 92 & & \\
\hline & Occasionally & 16 & 14.4 & 7 & 5.6 & 7.62 & $0.022^{*}$ \\
\hline & Always & 0 & 0 & 3 & 2.4 & & \\
\hline & Never & 100 & 90.1 & 115 & 92 & & \\
\hline Reaching for cheek while eating & Occasionally & 11 & 9.9 & 5 & 4 & 7.49 & $0.02^{*}$ \\
\hline & Always & 0 & 0 & 5 & 4 & & \\
\hline & Never & 109 & 98.2 & 119 & 95.2 & & \\
\hline Crying at night & Occasionally & 2 & 1.8 & 4 & 3.2 & 2.28 & $0.31^{\dagger}$ \\
\hline & Always & 0 & 0 & 2 & 1.6 & & \\
\hline & Never & 102 & 91.9 & 121 & 96.8 & & \\
\hline Crying during meals & Occasionally & 9 & 8.1 & 4 & 3.2 & 2.72 & $0.09^{\dagger}$ \\
\hline & Always & 0 & 0 & 0 & 0 & & \\
\hline & Never & 109 & 98.2 & 111 & 88.8 & & \\
\hline Earache at night & Occasionally & 2 & 1.8 & 10 & 8 & 8.55 & $0.014^{*}$ \\
\hline & Always & 0 & 0 & 4 & 3.2 & & \\
\hline & Never & 110 & 99.1 & 114 & 91.2 & & \\
\hline Earache at daytime & Occasionally & 1 & 0.9 & 7 & 5.6 & 7.76 & $0.02^{*}$ \\
\hline & Always & 0 & 0 & 4 & 3.2 & & \\
\hline & Never & 111 & 100 & 115 & 92 & & \\
\hline Earache during eating & Occasionally & 0 & 0 & 8 & 6.4 & 9.27 & $0.01^{*}$ \\
\hline & Always & 0 & 0 & 2 & 1.6 & & \\
\hline & Never & 15 & 13.5 & 95 & 76 & & \\
\hline Excessive salivation & Occasionally & 73 & 65.8 & 17 & 13.6 & 95.3 & $0.000^{*}$ \\
\hline & Always & 23 & 20.7 & 13 & 10.4 & & \\
\hline & Never & 45 & 40.5 & 116 & 92.8 & & \\
\hline Putting hand inside the mouth & Occasionally & 63 & 56.8 & 9 & 7.2 & 74.24 & $0.000^{*}$ \\
\hline & Always & 3 & 2.7 & 0 & 0 & & \\
\hline & Never & 101 & 91 & 107 & 85.6 & & \\
\hline Do you think your child has dental pain & Always & 9 & 8.1 & 18 & 14.4 & 3.35 & $0.18^{\dagger}$ \\
\hline & Occasionally & 1 & 0.9 & 0 & 0 & & \\
\hline
\end{tabular}


TABLE 2: Continued.

\begin{tabular}{|c|c|c|c|c|c|c|c|}
\hline \multirow{2}{*}{ Question } & \multirow{2}{*}{ Frequency } & \multicolumn{2}{|c|}{ Disabled children } & \multicolumn{2}{|c|}{ Normal children } & \multirow{2}{*}{ Chi-square } & \multirow{2}{*}{$P$ value } \\
\hline & & $n$ & $\%$ & $n$ & $\%$ & & \\
\hline \multirow{3}{*}{ How frequent is your child's dental pain } & Never & 101 & 91 & 110 & 88 & \multirow{3}{*}{0.55} & \multirow{3}{*}{$0.45^{\dagger}$} \\
\hline & Occasionally & 10 & 9 & 15 & 12 & & \\
\hline & Always & 0 & 0 & 0 & 0 & & \\
\hline \multirow{4}{*}{ How severe is your child's dental pain } & Never & 102 & 91.9 & 66 & 52.8 & \multirow{4}{*}{45.21} & \multirow{4}{*}{$0.000^{*}$} \\
\hline & Mild & 6 & 5.4 & 50 & 40 & & \\
\hline & Moderate & 3 & 2.7 & 7 & 5.6 & & \\
\hline & Severe & 0 & 0 & 2 & 1.6 & & \\
\hline \multirow{4}{*}{ When does pain occur } & Never & 102 & 91.9 & 66 & 52.8 & \multirow{4}{*}{45.33} & \multirow{4}{*}{$0.000^{*}$} \\
\hline & Mild & 5 & 4.5 & 48 & 38.4 & & \\
\hline & Moderate & 3 & 2.7 & 7 & 5.6 & & \\
\hline & Severe & 1 & 0.9 & 4 & 3.2 & & \\
\hline
\end{tabular}

* Statistically significant $(P<0.05)$.

${ }^{\dagger}$ Statistically not Significant $(P>0.05)$.

region while eating, a behavioral change depicting vague dental pain which they were unable to express otherwise. Typically developing children reported ear pain at night $(P=$ $0.014)$, during daytime $(P=0.02)$, and a few while eating $(P=0.01)$. In the entire study, excessive salivation in ID children during dental pain $(P=0.00)$ was one of the most important behavioral changes observed by the caregivers. Adding to this, the other significant behavioral change was the habit of placing their hand or objects inside the mouth $(P=0.00)$ (Table 2).

\section{Discussion}

According to the International Association for Study of Pain (IASP) [1], pain is defined as "an unpleasant sensory and emotional experience associated with actual or partial tissue damage." A reliable description of such pain is generally difficult in children and even more challenging in ID children. Intellectual disability is defined as mental retardation or impairment in the areas of development or cognitive activities [10].

Intellectual disability is "a disability characterized by significant limitations both in intellectual functioning and in adaptive behavior, which covers many everyday social and practical skills. This disability originates before the age of 18 " [11]. Dental problems are more common in people with special needs, sometimes not only because of the disability itself but also because of inadequate oral health care. These special children required special health care approaches as they had very poor oral hygiene. According to research and the literature, these children had physical, mental, sensory, behavioral, cognitive, emotional, and chronic medical conditions which required health care beyond the usual measures and which involved specialized knowledge, increased awareness, attention, and accommodation. Information about pain in children with cognitive impairment was always insufficient and less reliable for a dentist [11-13]. To gather any data related to pain the investigators or health care provider had to rely on the caregiver's perception depending on the level of cognitive impairment, and pain coping and expression varied in these special children [6].

Pain is a common experience and is a part of childhood. The identification and interpretation of dental pain in severe cognitive communication and motor impairments were challenging. We concluded that there is a high incidence of dental pain and treatment needs that are not catered to. In spite of parents and caregiver's educational qualifications, dental pain is rarely understood and treated; this was due to the other major chronic systemic illnesses the children undergo. Hence, dental pain in children goes unnoticed often and they are not brought to the dentist for routine checkup. Mostly caregivers identify dental pain based on the ID children change in behavior and bring it to the notice of the healthcare provider [14]. Hence, mostly ID children reach the dentist in an acute state of pain leaving very few options to save the teeth. Even the effective treatment options are compromised due to the lack of cooperation.

The data outcome of this study indicates that ID children have problem in brushing upper and lower teeth. This was because of fear and anxiety amongst intellectually disabled children in placing a foreign object into their mouth. Children should be trained patiently to overcome these problems which require a dentist's and a caregiver's cooperation. Reaching for cheek while eating and earache at night or during meals were also common behavioral changes during dental pain. The caregivers should understand these signs and bring the children to the dentist immediately because the pain expressed in such manner is mostly of acute nature. Most of the ID children had excessive salivation and the habit of placing their hand or objects inside the mouth during dental pain. These were the highly exhibited characters in intellectually disabled children. According to researches, an increase in dental caries causes more dental pain which leads to these pain related behavior. So caregivers and dentists have to work mutually to recognize specific changes in behavioral pattern [15]. 
Though this study was done based on research articles specializing on pediatric dentistry and cognitive impairment in children, it still had a number of limitations which include lack of professional assessment of ID children. Future studies including the comparison between different degrees of intellectual disability could further provide more specific conclusions.

\section{Conclusion}

Intellectually disabled children had more problems in brushing upper teeth and exhibited the habit of reaching for the cheek while eating. The prevalence of reporting dental pain was more in typically developing children than in intellectually disabled children.

\section{Conflict of Interests}

The authors declare that there is no conflict of interests regarding the publication of this paper.

\section{Acknowledgment}

The authors acknowledge Mr. Savan Unni for helping them organize the data collection.

\section{References}

[1] H. Merskey and N. Bogduk, Classification of Chronic Pain: Description of Chronic Pain Syndromes and Definitions of Pain Terms, IASP Press, Seattle, Wash, USA, 2nd edition, 1994.

[2] N. McIntosh, "Pain in the newborn, a possible new starting point," European Journal of Pediatrics, vol. 156, no. 3, pp. 173177, 1997.

[3] L. S. Franck, C. S. Greenberg, and B. Stevens, "Pain assessment in infants and children," Pediatric Clinics of North America, vol. 47, no. 3, pp. 487-512, 2000.

[4] P. Stallard, L. Williams, S. Lenton, and R. Velleman, "Pain in cognitively impaired, non-communicating children," Archives of Disease in Childhood, vol. 85, no. 6, pp. 460-462, 2001.

[5] K. L. Hadden and C. L. Von Baeyer, "Pain in children with cerebral palsy: common triggers and expressive behaviors," Pain, vol. 99, no. 1-2, pp. 281-288, 2002.

[6] D. Fanurik, J. L. Koh, M. L. Schmitz, R. D. Harrison, and T. M. Conrad, "Children with cognitive impairment: parent report of pain and coping," Journal of Developmental \& Behavioral Pediatrics, vol. 20, no. 4, pp. 228-234, 1999.

[7] American Psychiatric Association, Diagnostic and Statistical Manual of Mental Disorders, American Psychiatric Association, Washington, DC, USA, 4th edition, 1994.

[8] J. Versloot, J. S. J. Veerkamp, and J. Hoogstraten, "Dental discomfort questionnaire: assessment of dental discomfort and/or pain in very young children," Community Dentistry and Oral Epidemiology, vol. 34, no. 1, pp. 47-52, 2006.

[9] J. Scott and E. C. Huskisson, "Graphic representation of pain," Pain, vol. 2, no. 2, pp. 175-184, 1976.

[10] R. Luckasson, D. L. Coulter, and E. A. Polloway, Eds., Mental Retardation: Definition, Classification, and Systems of Supports, American Association on Mental Retardation, Washington, DC, USA, 1992.
[11] Kehitysvammalaki 519/1977, "Law of intellectual disabilities," American Association on Intellectual and Developmental Disabilities (AAIDD), 2009, http://www.aaidd.org/ content_100.cfm?navID=21, http://www.finlex.fi/fi/laki/alkup/ 1977/19770988.

[12] T. Calabro, "For people with special needs, good dental care is a challenge," May 2003, http://www.post-gazette.com/healthscience.

[13] F. A. Oredugba and Y. Akindayomi, "Oral health status and treatment needs of children and young adults attending a day centre for individuals with special health care needs," BMC Oral Health, vol. 8, article 30, 2008.

[14] S. Malviya, T. Voepel-Lewis, A. R. Tait et al., "Pain management in children with and without cognitive impairment following spine fusion surgery," Paediatric Anaesthesia, vol. 11, no. 4, pp. 453-458, 2001.

[15] S. M. Alaki and N. S. Bakry, "Dental pain in children with intellectual disabilities: caregivers' perspective," International Journal of Dentistry, vol. 2012, Article ID 701608, 7 pages, 2012. 


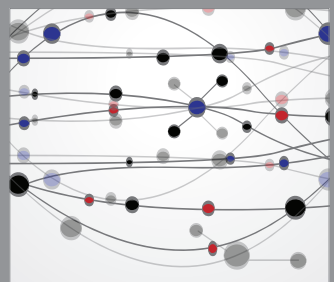

The Scientific World Journal
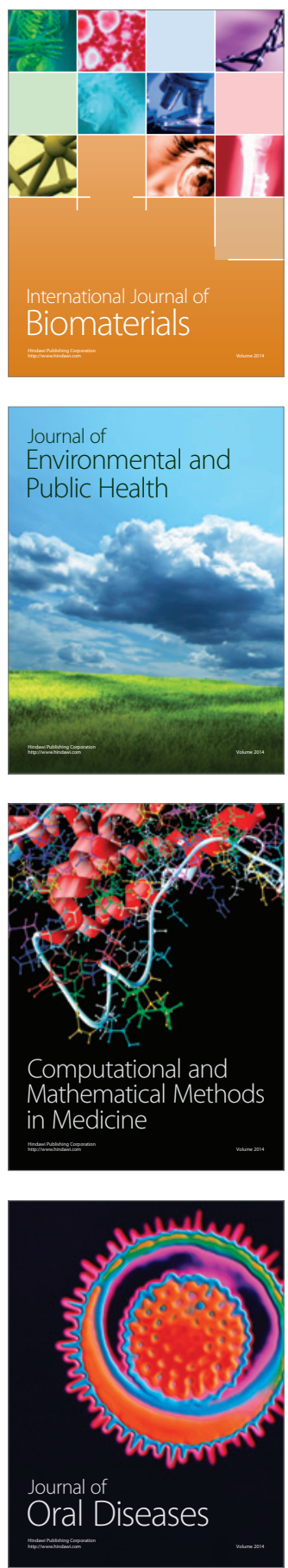
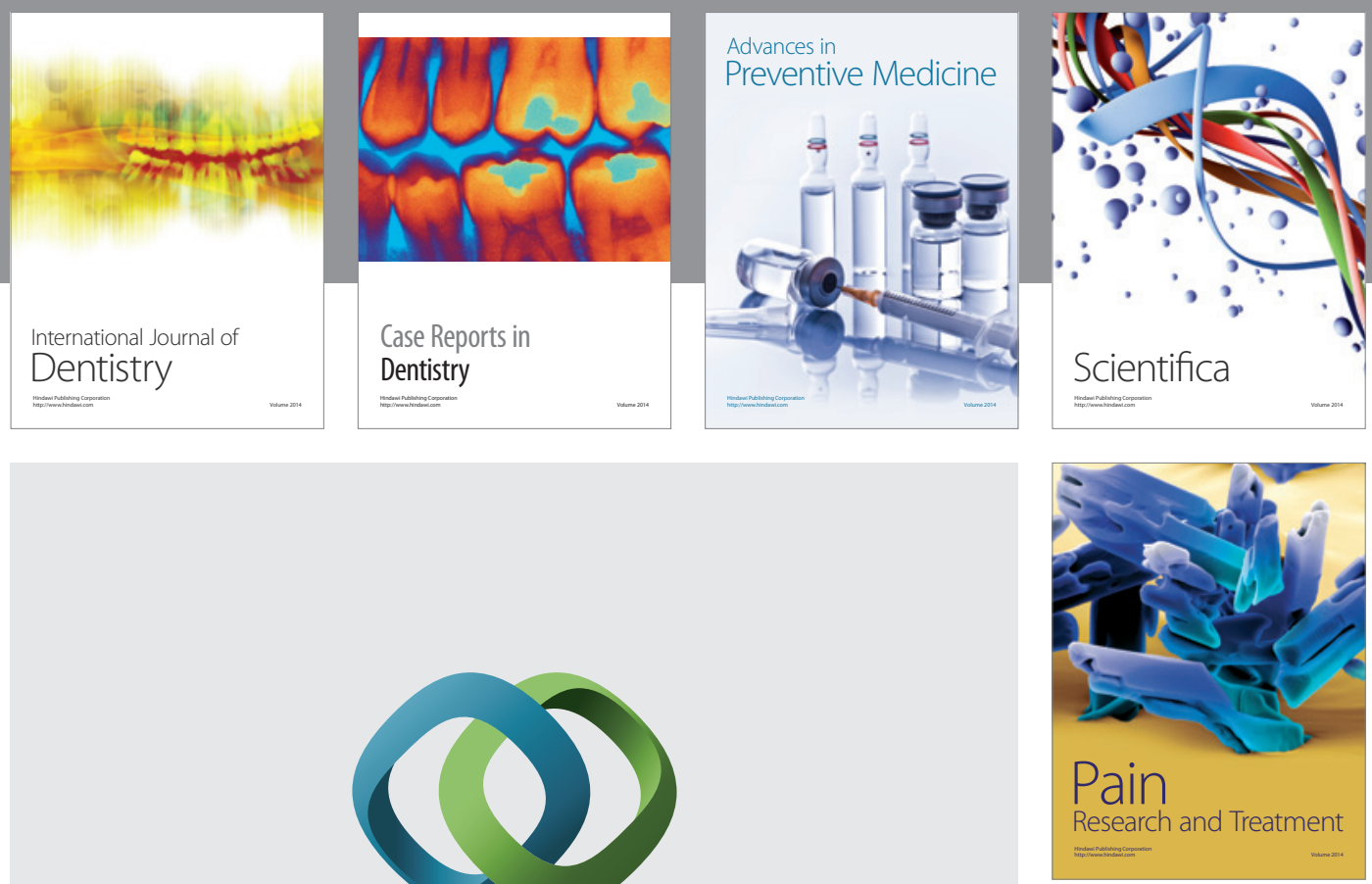

\section{Hindawi}

Submit your manuscripts at

http://www.hindawi.com
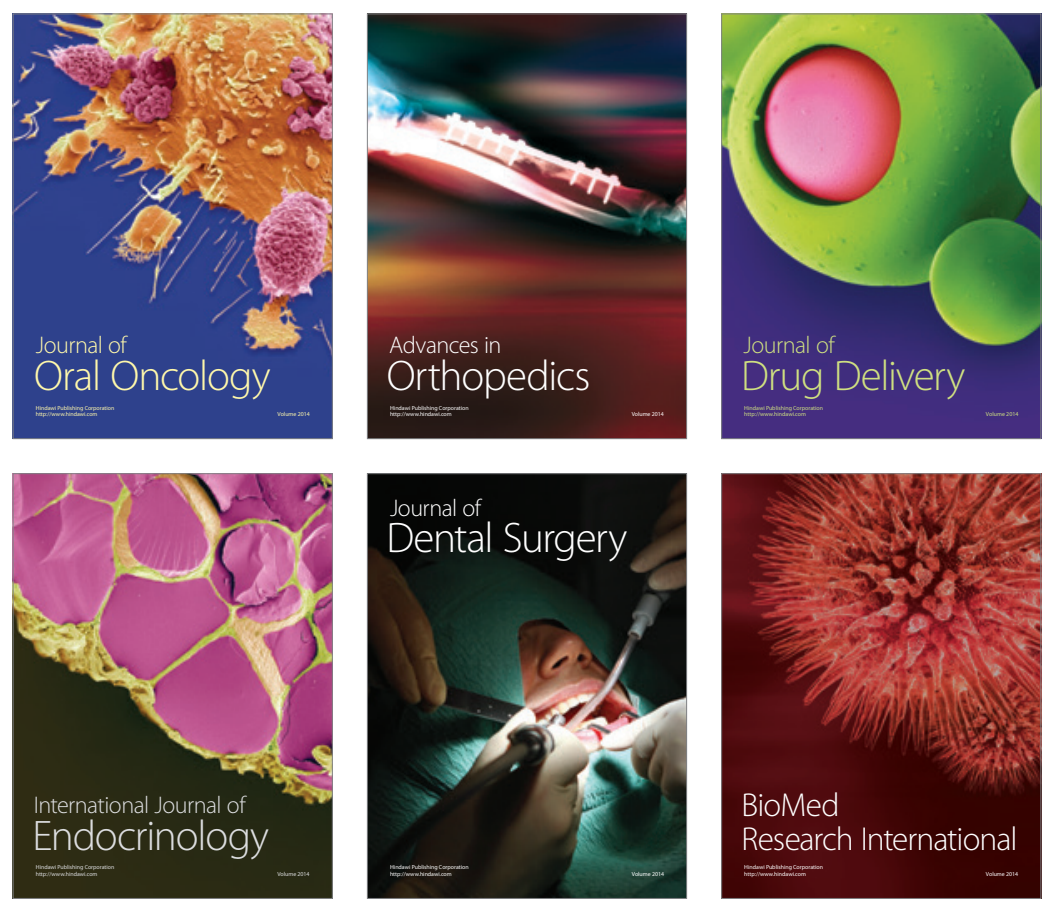

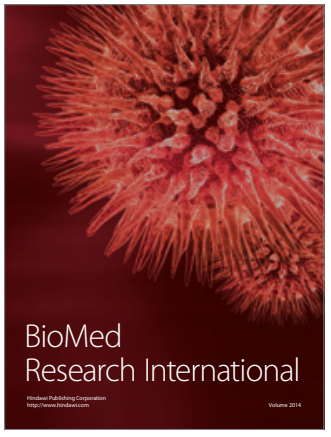

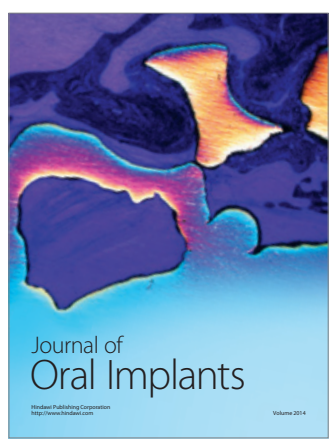
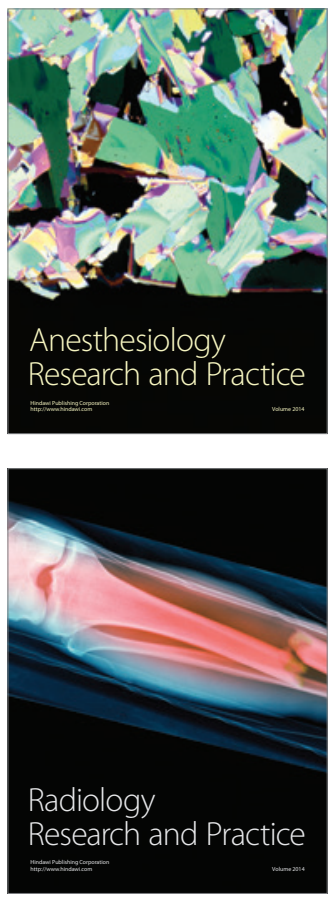